\title{
Regression of primary pulmonary hypertension
}

\author{
P. D. V. Bourdillon ${ }^{1}$ and C. M. Oakley \\ From The Department of Medicine (Clinical Cardiology), Royal Postgraduate Medical School, Hammersmith \\ Hospital, London
}

\begin{abstract}
A girl who presented in childhood with advanced primary pulmonary hypertension and whose condition later improved is described. This is the first time to our knowledge that documented regression of the disease has been reported.
\end{abstract}

Idiopathic pulmonary hypertension, including childhood and familial primary pulmonary hypertension, is usually a fatal disease. Wood (1956) reported an average survival of $3 \cdot 2$ years from the onset of symptoms in a series of 20 patients. A few patients live much longer and show relatively longterm stability, but even in these more fortunate cases eventual deterioration and death is still the rule. Nielsen and Fabricius (1961) reported 3 out of 14 patients who were still living 15 to 20 years after the onset of symptoms. Charters and Baker (1970) described a case of primary pulmonary hypertension in a man who died at the age of 25 years, 19 years after the onset of symptoms. In their huge series Wagenvoort and Wagenvoort (1970) recorded 4 out of 110 patients in whom symptoms had been present for between 20 and 29 years before death.

We report here a patient in whom primary pulmonary hypertension regressed after the disorder had reached an advanced stage. We have been unable to find any reports of comparable cases. The only other report of improvement was of a patient whose pulmonary hypertension was thought to be thromboembolic in origin (Wilcken, MacKenzie, and Goodwin, 1960): these authors recorded a drop in pulmonary artery pressure from $65 / 28$ to $40 / 20$ $\mathrm{mm} \mathrm{Hg}(8 \cdot 6 / 3.7$ to $5 \cdot 3 / 2.7 \mathrm{kPa})$ during anticoagulant treatment.

\section{Case report}

The patient was born at term after a normal pregnancy and uncomplicated delivery. Her development was normal and she had had no serious illnesses. There was

Received 29 September 1975.

${ }^{1}$ Present address: Wessex Cardiothoracic Centre, Western Hospital, Oakley Road, Shirley, Southampton. no relevant family history; the parents and a younger sister were healthy.

She had been apparently quite well until the age of 10 when in May 1966 she fainted momentarily. Between June 1966 and December 1966 she fainted six times, always when running or climbing stairs. Since the onset of the fainting episodes she had also noticed breathlessness on exertion and could not walk at a normal pace on the flat without dyspnoea.

The patient was first seen at Hammersmith Hospital in April 1967 at the age of 11 years and was then overweight $(40.4 \mathrm{~kg}$ and $145 \mathrm{~cm}$, on the 90 th centile for weight and the 50th centile for height), but looked fit. There were no signs of puberty. She was acyanotic and not clubbed. The heart rate and rhythm were normal; the blood pressure was $105 / 75 \mathrm{mmHg}(14 \cdot 0 / 10 \cdot 0 \mathrm{kPa})$ but she had signs of severe pulmonary hypertension. The jugular venous pressure showed a 6-cm ' $a$ ' wave. There was a pronounced right ventricular heave and pulmonary arterial pulsation with a palpable pulmonary component of the second sound. There was a right ventricular fourth sound, a pulmonary ejection click, and a soft, short, ejection systolic murmur. The pulmonary component of the second sound moved normally with respiration and there was no pulmonary regurgitant murmur. The lung fields were clear on auscultation.

\section{Investigations}

Haematological and biochemical investigations were all normal. The electroencephalogram showed some generalized disorganization but no localizing features. The electrocardiogram showed severe right ventricular hypertrophy with widespread $\mathrm{T}$ wave changes (Fig. 1). The chest radiograph showed slight cardiac enlargement with prominent main pulmonary arteries and clear lung fields with normal or reduced vascularity (Fig. 2a).

Cardiac catheterization had already been carried out elsewhere in January 1967. The results (see Table) confirmed that she had severe pulmonary hypertension without any evidence of structural heart disease. 


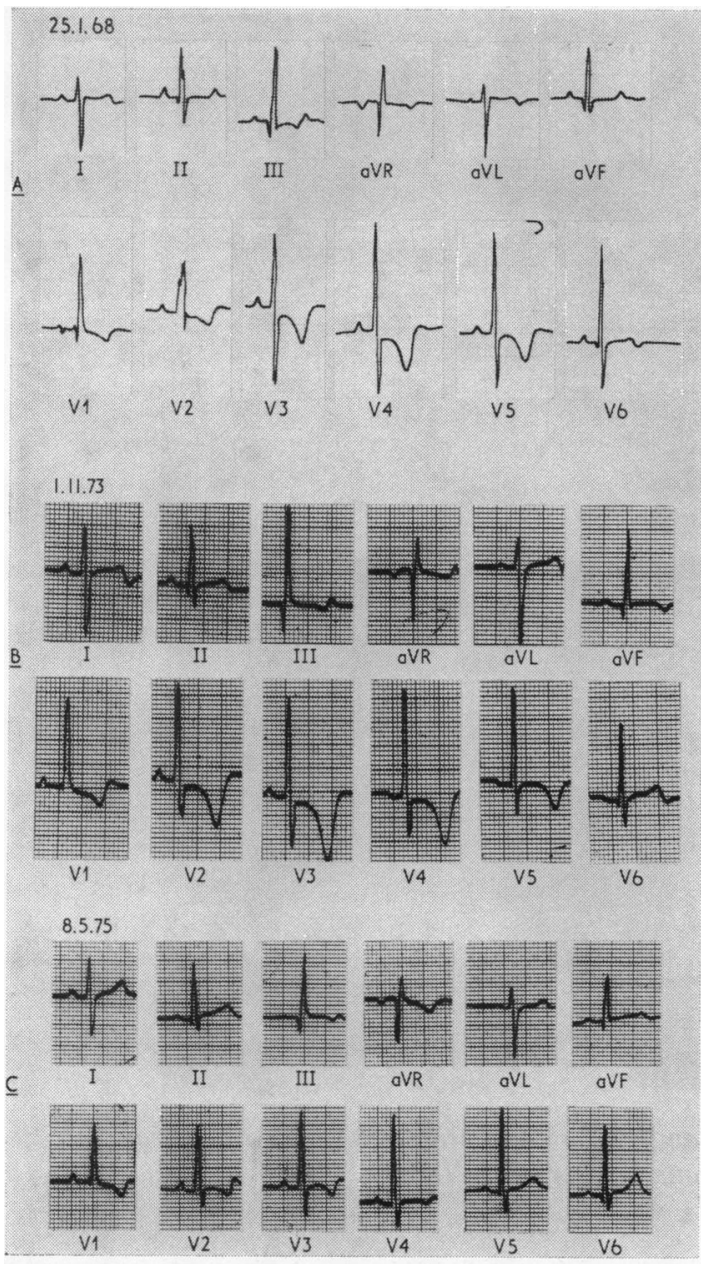

FIG. 1 Comparison of $(A)$ electrocardiograms recorded in 1968 (when aged 11 years), (B) 1973 (aged 17), and (C) 1975 (aged 19), suggests decrease in severity of right ventricular hypertrophy between 1973 and 1975. (Electrocardiograms all recorded at normal standardization, i.e. $10 \mathrm{~mm}=1 \mathrm{mV}$.)

The diagnosis of primary pulmonary hypertension was accepted and treatment with oral anticoagulants was started.

\section{Progress}

From 1967 to 1969 the patient continued to be breathless and feel faint on exertion. She was readmitted to Hammersmith Hospital in August 1969 because of gradual deterioration after a syncopal attack in July 1969 and considerable decrease in exercise tolerance. Physical findings were similar to those in 1967 except that she was even more obese and an early diastolic murmur in the pulmonary area had appeared. Phonocardiograms re- corded at this time are shown in Fig. 3A. The electrocardiogram was unchanged from 1967. Chest $x$-ray examination, however, showed a further increase in heart size. A perfusion lung scan was within normal limits. Right heart catheterization was repeated (Table). A pulmonary angiogram showed normal peripheral pulmonary arteries but dilatation of the main pulmonary arteries. It was thought that pulmonary thromboembolism could be excluded as a cause of her recent deterioration. She was, however, continued on anticoagulants and put on an 800-calorie diet.

The patient continued to have syncopal episodes in 1970 and 1971 and had to limit her activities even further. The early diastolic murmur in the pulmonary area became louder. Then, inexplicably, the slow deterioration was halted and she gradually improved. Her last syncopal episode was in 1971. In retrospect we think that the improvement probably started in 1972, when she was 16. Subjective improvement was first noted at her clinic visit in September 1972. Disappearance of the pulmonary regurgitant murmur and loss of ejection click were noted in May 1973.

In 1973 she left school, and her father bought her a car because of her disability. She learned to drive and drove to and from a sedentary job as a clerk with a travel firm.

By 1975 she had become virtually asymptomatic and now leads a normal, active life. She was readmitted to Hammersmith Hospital for reinvestigation. At 19 she was a fit-looking, well-developed young woman, still slightly obese. The cardiac findings were totally changed. The giant venous ' $a$ ' wave in the neck, the pulmonary ejection click, and the murmur of pulmonary regurgitation had all disappeared. The right ventricular heave and the palpable pulmonary closure sound were less prominent. The phonocardiogram (Fig. 3B) showed only a soft systolic murmur, with a prominent pulmonary component of the second sound, but no ejection click or early diastolic murmur. The electrocardiogram had changed considerably, with reduction in voltage of the $\mathbf{R}$ waves in the right praecordial leads and improvement in the previously widespread, steeply inverted $T$ waves (Fig. 1). The chest $x$-ray picture had changed. The steadily enlarging heart seen in films taken between 1967 and 1971 (Fig. 2) was reduced to normal size. Cardiac catheterization was repeated (Table). The pulmonary angiogram was unchanged and still showed dilated main pulmonary arteries with normal peripheral arteries without obstruction. Ventilation and perfusion lung scans showed no significant abnormality. The echocardiogram showed that the movement of the interventricular septum was normal.

\section{Haemodynamic data (Table)}

Between 1967 and 1969 the pulmonary arterial pressure was recorded three times and was at or near systemic level at rest on each occasion. Because of her parlous state and the possible risks involved no exercise tests were performed. There was no fall in the pulmonary arterial pressure with administration of 100 per cent 


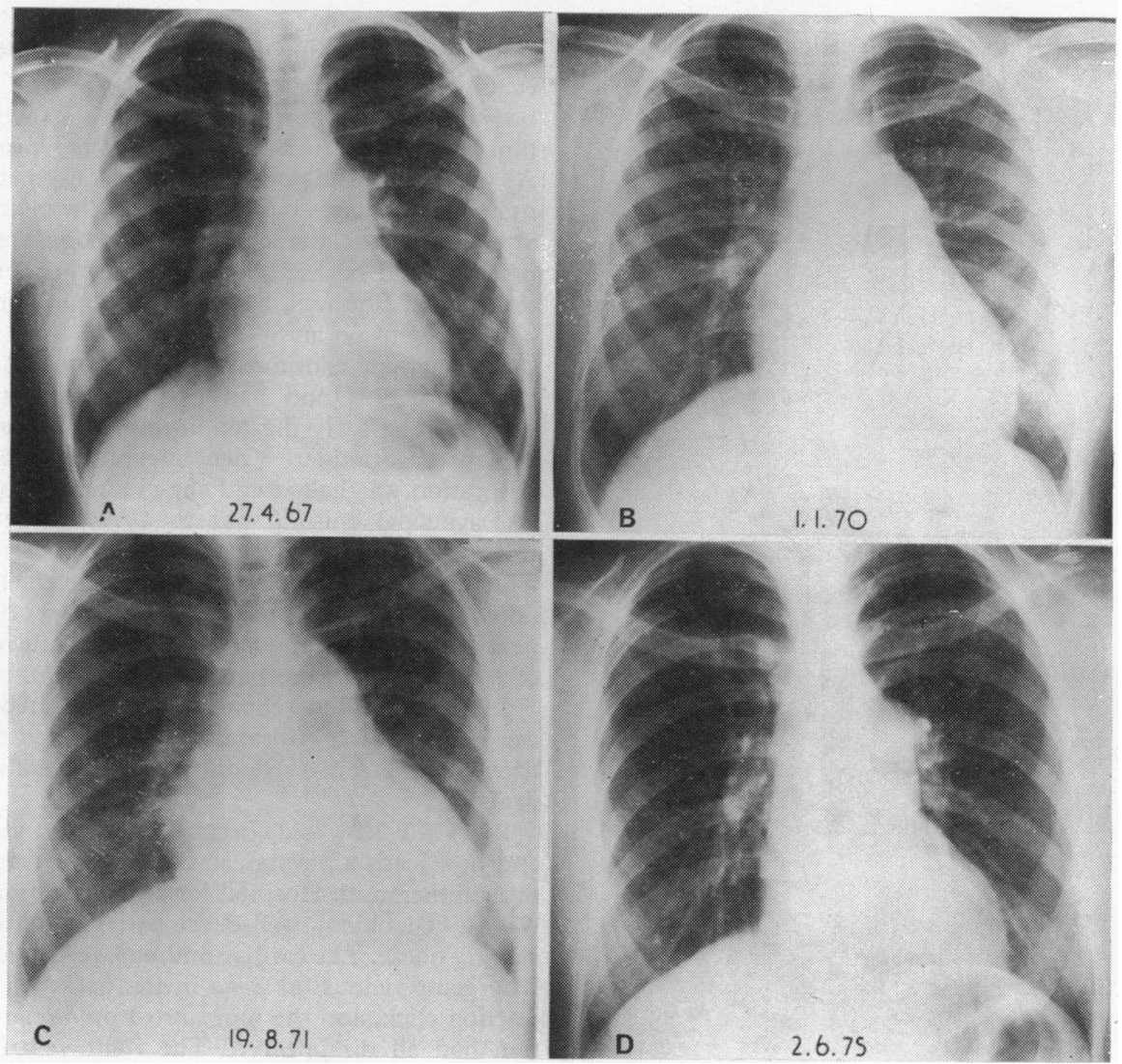

FIG. 2 Chest $\mathrm{X}$-rays taken in 1967, 1970, 1971, and 1975 show a progressive increase in heart size from 1967 to 1971 (Fig. $A, B, C$ ) with a pronounced decrease in $D$.

oxygen. Bicycle ergometry in 1969 showed that her maximum work load was only $200 \mathrm{kpm} /$ minute. She was then stopped by dyspnoea with a pulse rate of $150 / \mathrm{min}$. The transseptal left heart catheterization carried out in 1967 excluded any abnormality in the left heart chambers or septal defect.

At her fourth study in 1975 the pulmonary artery pressure had fallen to just above normal with a normal systemic pressure and the previously very reduced cardiac output had risen to low normal limits. Bicycle ergometry showed that her exercise performance was now within normal limits (Fig. 4). Lung function is now normal apart from low CO transfer which is 19.3 (predicted $25 \cdot 7$ to $32.9 \mathrm{ml} / \mathrm{min}$ per $\mathrm{mmHg}$ ) consistent with a slight loss of pulmonary vascular bed.

The evidence of true regression of her pulmonary vascular disease was considered to be irrefutable, though it was too early to conclude that she was 'normal' as 'cured'.

\section{Discussion}

This case of apparent improvement from a present- ing severe state of primary pulmonary hypertension raises a number of points worthy of discussion, particularly in relation to the possible causes or the mechanism of raised pulmonary vascular resistance.

The diagnosis of primary pulmonary hypertension is made only after exclusion of identifiable causes of pulmonary hypertension-in particular, postcapillary pulmonary hypertension caused by mitral valve disease or left heart failure, and precapillary pulmonary hypertension caused by congenital septal defects with the Eisenmenger reaction. Pulmonary thromboembolism or primary lung disease also need to be eliminated. In our patient organic heart disease had been excluded and there was no evidence of primary lung disease. Pulmonary thromboembolism was a theoretical possibility but was most unlikely in a girl of 11 , and was excluded by the normal pulmonary angiogram and lung scan in 1969 (Wilson et al., 1973). The lack of respiratory illness or haemoptyses, repeatedly clear lung fields on $x$-ray examination, and normal 
TABLE Cardiac catheterization data recorded in 1967 (2 procedures), 1969 and 1975

\begin{tabular}{|c|c|c|c|c|c|c|c|c|c|c|c|c|}
\hline & $S V C$ & $I V C$ & $R A$ & $R V$ & $P A$ & $P V$ & $L A$ & $L V$ & $S A$ & $\begin{array}{l}S A \\
(100 \%\end{array}$ & $\left.\mathrm{O}_{2}\right)^{C I}$ & $T P R$ \\
\hline $\begin{array}{l}1967(\mathrm{a}) \\
\text { Pressures (mmHg) } \\
\mathrm{O}_{2} \text { saturation }(\%)\end{array}$ & $\overline{74}$ & $\overline{71}$ & $\begin{array}{l}M 7 \cdot 5 \\
68\end{array}$ & $\overline{67}$ & $\begin{array}{l}76 / 40 \\
67\end{array}$ & - & - & - & $\begin{array}{l}100 / 70 \\
89\end{array}$ & $\overline{99}$ & - & - \\
\hline $\begin{array}{l}1967(\mathrm{~b}) \\
\text { Pressures }(\mathrm{mmHg}) \\
\mathrm{O}_{2} \text { saturation }(\%)\end{array}$ & - & - & $\begin{array}{l}\text { M } 5 \\
-\end{array}$ & $\begin{array}{l}96 / 8 \\
-\end{array}$ & $\begin{array}{l}100 / 60 \\
M 80 \\
62\end{array}$ & 90 & $\begin{array}{l}\text { M } 7 \\
94\end{array}$ & $106 / 8$ & $\begin{array}{l}120 / 75 \\
87\end{array}$ & - & - & - \\
\hline $\begin{array}{l}1969 \\
\text { Pressures }(\mathrm{mmHg}) \\
\mathrm{O}_{2} \text { saturation }(\%)\end{array}$ & $\begin{array}{l}- \\
-\end{array}$ & $\begin{array}{l}- \\
-\end{array}$ & $\begin{array}{l}\text { M } 10 \\
-\end{array}$ & $\begin{array}{l}95 / 12 \\
-\end{array}$ & $\begin{array}{l}95 / 39 \\
M 58 \\
64\end{array}$ & $\begin{array}{l}- \\
-\end{array}$ & $\begin{array}{l}- \\
-\end{array}$ & $\begin{array}{l}- \\
-\end{array}$ & $\begin{array}{l}100 / 70 \\
97\end{array}$ & - & 1.5 & $17 \cdot 0$ \\
\hline $\begin{array}{l}1975 \\
\text { Pressures (mmHg) } \\
\mathrm{O}_{2} \text { saturation }(\%)\end{array}$ & $\begin{array}{l}- \\
-\end{array}$ & $\begin{array}{l}- \\
-\end{array}$ & $\begin{array}{l}\text { M } 2 \\
-\end{array}$ & $\begin{array}{l}40 / 4 \\
-\end{array}$ & $\begin{array}{l}40 / 14 \\
\text { M } 24 \\
66\end{array}$ & $\begin{array}{l}- \\
-\end{array}$ & $\begin{array}{l}- \\
-\end{array}$ & $\begin{array}{l}- \\
-\end{array}$ & $\begin{array}{l}110 / 70 \\
97\end{array}$ & - & $2 \cdot 3$ & 3.8 \\
\hline
\end{tabular}

*Sphygmomanometer cuff measurement. $R A=$ right atrium; $R V=$ right ventricle; $P A=$ pulmonary artery; $S A=$ systemic artery; $L A=$ left atrium; $L V=$ left ventricle; $I V C=$ inferior vena cava; $S V C=$ superior vena cava; $P V=$ pulmonary vein; $\mathrm{M}=$ mean; $100 \% \mathrm{O}_{2}$ indicates administration of $100 \% \mathrm{O}_{2}$ at time of sampling; $\mathrm{CI}=$ cardiac index in $1 / \mathrm{min}$ per $\mathrm{m}^{2} ; \mathrm{TPR}=$ total pulmonary resistance in units $/ \mathrm{m}^{2}$.

Conversion from Traditional units to SI units: $1 \mathrm{mmHg} \approx 0.133 \mathrm{kPa}$.

lung scans made pulmonary venous obstruction (as in pulmonary veno-occlusive disease) extremely unlikely in our patient.

It is unlikely that the anticoagulants were directly relevant to the patient's recovery or that the association between treatment and improvement points to a thromboembolic origin of the pulmonary hypertension. It was hoped that anticoagulation would prevent pulmonary arterial thrombosis of thromboembolism as a secondary complication of the advanced stages of the disorder and that it might, therefore, prolong life (Wagenvoort and Wagenvoort, 1970). This is disputed by Walcott, Burchell, and Brown (1970) who noted in a retrospective study of 23 patients with primary pulmonary hypertension that anticoagulation did not appear to alter the natural history of the disease or the survival time. In the absence of specific therapy for this disease of undetermined aetiology, however, we believe that oral anticoagulants should be prescribed in idiopathic pulmonary hypertension and continued indefinitely.

Primary pulmonary hypertension is commonest in young women-usually in those who have been pregnant. In childhood, girls and boys are equally affected; the disorder is sometimes familial, and it may occur in sibs. The nature of the underlying disease process is still undetermined. Though a congenital abnormality in the pulmonary arterial wall remains a possibility, Heath and Edwards
(1960), Roberts (1963), and Wagenvoort and Wagenvoort (1970) showed that in most patients (including children) the pulmonary hypertension was not apparently present from birth but was acquired. Subramanian et al. (1974) found the 'adult' pattern of fragmented elastic fibres in the wall of the main pulmonary arteries in all of their 11 cases. This observation indicated that the disease had been acquired after a postnatal and childhood interval of low pulmonary artery pressure even in the 6 of their patients who died before the age of 16 .

A family predisposition to the development of the disease in childhood sheds no light on aetiology, but these cases sometimes survive for a relatively long time (Fleming, 1960; Melmon and Braunwald, 1963). Wagenvoort and Wagenvoort (1970) described 11 such familial cases and from the published reports collected 47 other cases from 20 different families. There was no family history associated with our patient.

Farrar (1963) and Wade and Atukorale (1975) have contended that the disease is part of an autoimmune process. This is supported by the association of pulmonary hypertension with rheumatoid and other collagen diseases as well as with Raynaud's phenomenon as described by Walcott et al. (1970) and by Wagenvoort and Wagenvoort (1970). Both of Trell's cases (1973) of primary pulmonary hypertension with an unusually long duration had Raynaud's phenomenon. There was no evidence of 


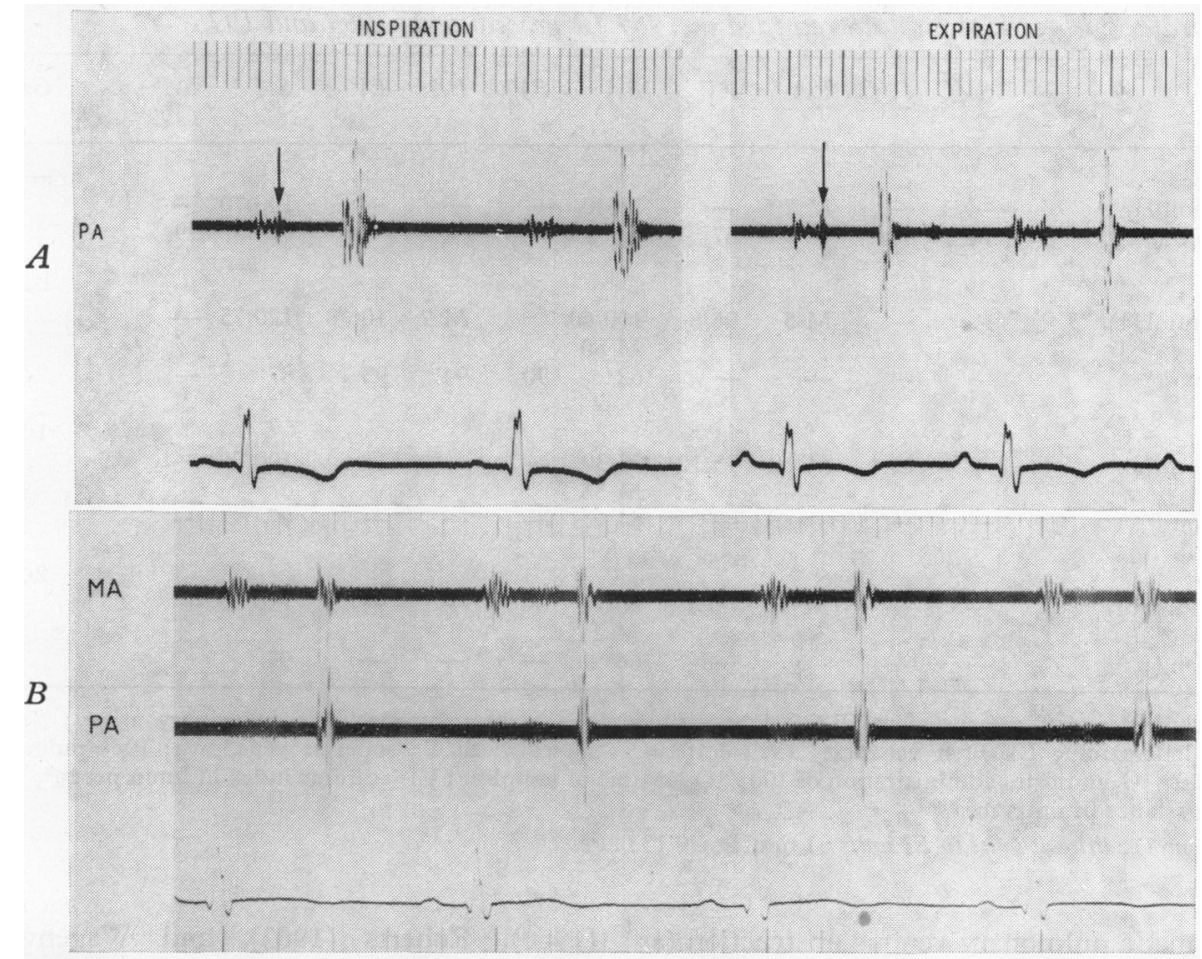

FIG. 3 Phonocardiograms recorded in 1969 (A) show loud pulmonary component of second sound which moves normally with respiration, and an ejection click (arrowed). Early diastolic murmur, then clinically prominent, does not show clearly. Phonocardiogram in 1975 (B) shows only soft systolic murmur. The ejection click has gone. The pulmonary component of second sound still appears to be loud. $M A=$ mitral area. $P A=$ pulmonary area.

collagen vascular disease in the patient described here. Farrar also noted that in some cases the onset of the disease seemed to be preceded by a virus-like illness, and this association was also mentioned by Walcott and his colleagues (1970). Again there was no history of such an illness in our patient before the onset of her symptoms.

The use of the anorectic drug aminorex fumarate (Menocil) has been implicated in some cases of pulmonary hypertension but there was no history of the use of this drug or of other 'slimming' drugs in our patient whose disease started some years before she had any interest in slimming.

Wood (1952) was probably the first to suggest that pulmonary hypertension might be vasoconstrictive in origin and a self-perpetuating response to some initiating degree of pulmonary hypertension itself. Evans, Short, and Bedford (1957), and Wade and Ball (1957) supported this view and Short (1959) cited earlier physiological work which showed that, like smooth muscle in other situations, the vascular coats of arteries react to a stretching force by constriction. Wood (1959) found that patients with primary pulmonary hypertension responded to injection of acetylcholine into the pulmonary artery by a brisk fall in pulmonary artery pressure, and this seemed to support the concept of vasoconstriction. The pathological work of Wagenvoort and Wagenvoort (1970) led them to support a vasoconstrictive pathogenesis and to reintroduce Wood's term 'vasoconstrictive pulmonary hypertension' to describe this group with primary pulmonary hypertension. The notion that there exists an individual susceptibility or hyperreactivity of the muscular pulmonary arterioles in patients who develop pulmonary hypertension in response to the various stimuli that may trigger pulmonary vasoconstriction is all that is known about causation. Such stimuli may include a high pulmonary artery pressure and pulse pressure associated with intracardiac shunts, increased flow, polycythaemia, hypoxia, and possibly also sexual maturation in the female and 


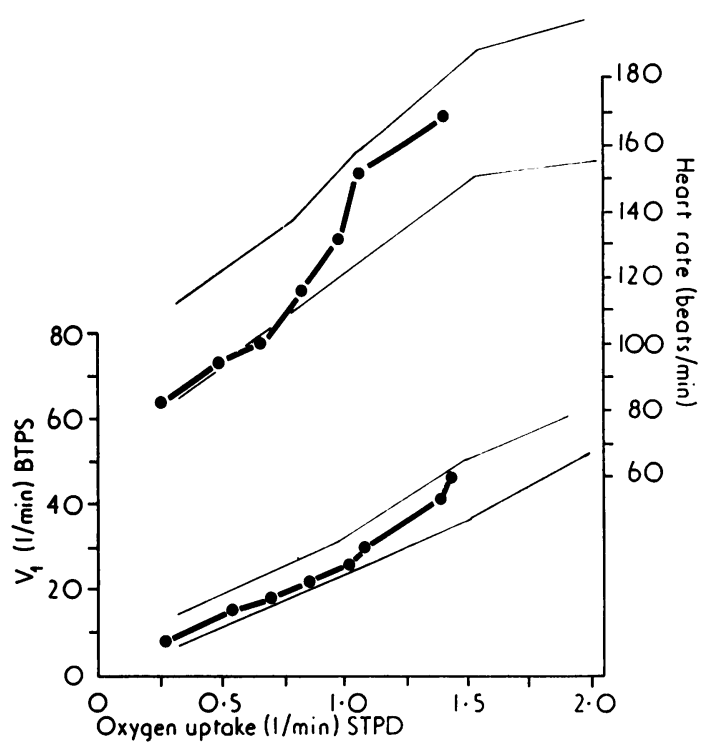

FIG. 4 Result of progressive exercise test in 1975. Increments in heart rate (above) and ventilation (below) fell within expected normal range (fine lines) for increase in oxygen uptake achieved.

pregnancy. Reversal of such a postulated vicious spiral could possibly explain the recovery in our patient.

A higher pulmonary artery pressure than normal is found in most dwellers at high altitude than in those who live at sea level. This is normally asymptomatic and benign (Grover et al., 1966). The same authors described the reversal of unusually severe asymptomatic pulmonary hypertension in a patient who had lived at high altitude but moved to sea level, and attributed this to relief from the hypoxic stimulus to pulmonary vasoconstriction that had been present at altitude. It may be of significance that the apparent deterioration in our patient's condition in 1969 occurred after a visit to Switzerland.

The later symptomatic and objective improvement described coincided with a late menarche at the age of 15. This is surprising in the light of the prevalence of idiopathic pulmonary hypertension in adult women and of its relatively common occurrence after pregnancy in contrast to the relative rarity and equal sex ratio in children.

Pregnancy is a serious hazard in pulmonary hypertension. These patients are advised to avoid pregnancy and it is our practice to carry out tubal ligation. Though tubal ligation had originally been planned for our patient and the original advice to avoid pregnancy has been upheld, we no longer feel justified in recommending sterilization. The case is without parallel in our experience, but provided her improvement is maintained over the next few years then it may even be reasonabie for her to consider pregnancy, though we feel uneasy about the risk of pregnancy then provoking a recrudescence of her disease.

\section{References}

Charters, A. D., and Baker, W. de C. (1970). Primary pulmonary hypertension of unusually long duration. British Heart fournal, 32, 130.

Evans, W., Short, D. S., and Bedford, D. E. (1957). Solitary pulmonary hypertension. British Heart fournal, 19, 93.

Farrar, J. F. (1963). Idiopathic pulmonary hypertension. American Heart fournal, 66, 128.

Fleming, H. (1960). Primary pulmonary hypertension in eight patients including a mother and her daughter. Australasian Annals of Medicine, 9, 18.

Grover, R. F., Vogel, J. H. K., Voigt, G. C., and Blount, S. G. (1966). Reversal of high altitude pulmonary hypertension. American fournal of Cardiology, 18, 928.

Heath, D., and Edwards, J. E. (1960). Configuration of elastic tissue of pulmonary trunk in idiopathic pulmonary hypertension. Circulation, 21, 59.

Melmon, K. L., and Braunwald, E. (1963). Familial pulmonary hypertension. New England fournal of Medicine, 269, 770.

Nielsen, N. C., and Fabricius, J. (1961). Primary pulmonary hypertension with special reference to prognosis. Acta Medica Scandinavica, 170, 731.

Roberts, W. C. (1963). The histologic structure of the pulmonary trunk in patients with 'primary' pulmonary hypertension. American Heart fournal, 65, 230.

Short, D. S. (1959). The application of arteriography to the pathological study of pulmonary hypertension. In Pulmonary Circulation, p. 240. Ed. by W. R. Adams and I. Veith. Grune and Stratton, New York.

Subramanian, N., Bathviziam, A., Sukumar, I. P., Krishnaswami, S., and Cherian G. (1974). Primary pulmonary hypertension. A clinicopathological study of 11 cases. Indian Heart fournal, 26, Suppl., p. 171.

Trell, E. (1973). Benign idiopathic pulmonary hypertension. Acta Medica Scandinavica, 193, 137.

Wade, G., and Atukorale, D. (1975). Observations on the aetiology of unexplained or primary pulmonary hypertension (abstract). British Heart fournal, 37, 550.

Wade, G., and Ball, J. (1957). Unexplained pulmonary hypertension. Quarterly fournal of Medicine, 26, 83.

Wagenvoort, C. A., and Wagenvoort, N. (1970). Primary pulmonary hypertension. A pathologic study of the lung vessels in 156 clinically diagnosed cases. Circulation, 42, 1163.

Walcott, G., Burchell, H. B., and Brown, A. L. (1970). Primary pulmonary hypertension. American fournal of Medicine, 49, 70.

Wilcken, D. E. L., MacKenzie, K. M., and Goodwin, J. F. (1960). Anticoagulant treatment of obliterative pulmonary hypertension. Lancet, 2, 781. 
Wilson, A. G., Harris, C. N., Lavender, J. P., and Oakley, C. N. (1973). Perfusion lung scanning in obliterative pulmonary hypertension. British Heart fournal, 35, 917.

Wood, P. (1952). Pulmonary hypertension. British Medical Bulletin, 8, 348.

Wood, P. (1956). Primary pulmonary hypertension. In Diseases of the Heart and Circulation, 2nd ed., p. 83. Eyre and Spottiswoode, London.
Wood, P. (1959). The vasoconstrictive factor in pulmonary hypertension. In Pulmonary Circulation, p. 297. Ed. by W. R. Adams and I. Veith. Grune and Stratton, New York.

Requests for reprints to Dr. C. M. Oakley, Royal Postgraduate Medical School, Hammersmith Hospital, London W12 0HS. 